\title{
IBM PEMBERDAYAAN MASYARAKAT NON PRODUKTIF MELALUI KETERAMPILAN PEMBUATAN KONGFLAKES (SINGKONG FLAKES)
}

\section{IBM EMPOWERMENT OF NON-PRODUCTIVE SOCIETY THROUGH SKILL MAKING KONGFLAKES (SINGKONG FLAKES)}

\author{
D Widiastuti'1a, E Herlina ${ }^{1}$, dan AH Mulyati \\ 1Program Studi Kimia, Fakultas Matematika dan Ilmu Pengetahuan Alam, \\ Universitas Pakuan, Jl. Pakuan P.O Box 452 Bogor 16143 Indonesia \\ a Korespondensi: Diana Widiastuti, Email: dianawidi25@gmail.com \\ (Diterima: 20-02-2018; Ditelaah: 20-02-2018; Disetujui: 06-06-2018)
}

\begin{abstract}
Department of Chemistry, Pakuan University in 2015 through funding from Badan Penelitian, Pengembangan dan Penerapan Ilmu Pengetahuan dan Teknologi (BP3Iptek) West Java Province has successfully developed functional food product made from cassava flour so named "Kongflakes" (Cassava Flakes). Department of Chemistry, Faculty of Mathematics and Natural Sciences provides an alternative program to improve the skill of making Kongflakes to the society. The resulting Kongflakes is a high value product, so that it can overcome the welfare of Karadenan society, especially cassava farmers and residents who erratically income become Kongflakes entrepreneurs. Kongflakes produced by 2 groups of PKK in Karadenan of Kabupaten Bogor, kongflakes is a ready-to-eat food product that can serve as one of the substitute for a practical and nutritious breakfast, that can be produced on a large scale that can help improve the family economy and increase the sale value of cassava in the area.
\end{abstract}

Keywords: cassava, kongflakes, welfare society.

\begin{abstract}
ABSTRAK
Program Studi Kimia Universitas Pakuan pada Tahun 2015 melalui dana dari Badan Penelitian, Pengembangan dan Penerapan Ilmu Pengetahuan dan Teknologi (BP3Iptek) Provinsi Jawa Barat telah berhasil mengembangkan produk pangan fungsional dibuat dari tepung singkong sehingga diberi nama "Kongflakes" (Singkong Flakes). Program Studi Kimia Fakultas MIPA memberikan alternatif suatu program untuk peningkatan keterampilan membuat Kongflakes kepada masyarakat. Kongflakes yang dihasilkan adalah berupa produk yang bernilai jual tinggi, sehingga dapat mengatasi kesejahteraan pada masyarakat kelurahan Karadenan terutama petani singkong dan penduduk yang berpenghasilan tidak menentu menjadi pengusaha Kongflakes. Kongflakes diproduksi oleh 2 kelompok PKK di Kelurahan Karadenan Kabupaten Bogor, kongflakes merupakan produk pangan siap santap yang dapat dijadikan sebagai salah satu pengganti sarapan yang praktis dan bergizi tinggi, kongflakes dapat diproduksi dalam skala besar sehingga dapat membantu meningkatkan perekonomian keluarga serta meningkatkan nilai jual singkong di daerah tersebut.
\end{abstract}

Kata kunci: singkong, kongflakes, kesejahteraan masyarakat.

Widiastuti, D., Herlina, E., \& Mulyati, A. H. (2018). IBM Pemberdayaan Masyarakat Non Produktif Melalui Keterampilan Pembuatan Kongflakes (Singkong Flakes). Qardhul Hasan: Media Pengabdian kepada Masyarakat 4(2): 90-96. 


\section{PENDAHULUAN}

Program Studi Kimia Universitas Pakuan pada Tahun 2015 melalui dana dari Badan Penelitian, Pengembangan dan Penerapan Ilmu Pengetahuan dan Teknologi (BP3Iptek) Provinsi Jawa Barat telah mengembangkan produk sereal siap santap digemari oleh masyarakat yang semakin menginginkan kepraktisan dan kemudahan terutama untuk sarapan pagi. Produk pangan fungsional tersebut adalah flakes yang dibuat dari tepung singkong sehingga diberi nama "Kongflakes" (Singkong Flakes).

Penelitian yang dibayai dari BP3iptek telah mendapatkan formula terbaik dan pembuatan Kongflakes manual, Proses pembuatan Kongflakes meliputi pencampuran bahan, pemanasan, pendinginan, pembentukan lembaran, dan pencetakan serta pemanggangan. Pembuatan produk Kongflakes dilakukan dengan mengukus tepung singkong selama dua jam atau lebih, kemudian dipipihkan di antara dua rol baja, setelah itu dikeringkan dan dipanggang pada suhu tinggi. Bentuk flakes dapat dilihat pada Gambar 1.

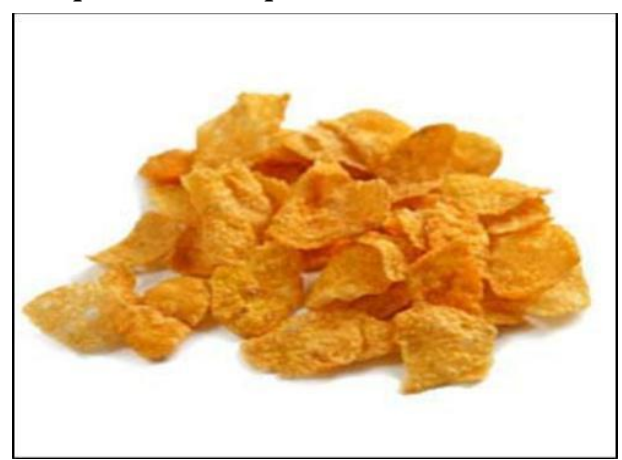

\section{Gambar 1 Flakes}

Setelah sukses mendapatkan formula yang tepat untuk membuat Kongflakes maka Program Studi Kimia Fakultas MIPA memberikan alternatif suatu program untuk peningkatan keterampilan membuat Kongflakes kepada masysarakat. Kongflakes yang dibuat akan memberikan nilai tambah pada masyarakat kelurahan Karadenan jika ditinjau dari 2 sisi yang berbeda. Pertama, melalui pengolahan singkong yang selama ini menjadi tepung tapioka dengan harga jual yang sangat rendah dijadikan alternatif lain menjadi tepung singkong untuk memproduksi Kongflakes yang bernilai jual tinggi sehingga dapat mengatasi kesejahteraan petani singkong. Kedua, dapat mengatasi masalah penduduk yang berpenghasilan tidak menentu menjadi pengusaha Kongflakes.

Berdasarkan informasi yang kami peroleh dari lampiran surat Lurah Karadenan nomor 500/71-Kel tanggal 15 April 2016 perihal Kerjasama Pengabdian masyarakat tentang profil Kelurahan Karadenan, maka kami akan menjadikan kelompok pengajin tapioka di Kaum Pandak Kelurahan Karadenan sebagai mitra untuk diberikan keterampilan. Pada kesempatan sosialisasi kami telah membentuk 2 kelompok mitra pengrajin tapioka, di Kaum Pandak RT.001/002 dan Kaum Pandak RT.002/002 Kelurahan karadenan Kecamatan Cibinong kabupaten Bogor sebagai model Pemberdayaan masyarakat.

Berdasarkan hal di atas maka disepakati (tim pengusul dan mitra) dapat disimpulkan bahwa penentuan masalah prioritas dilakukan dengan melihat dan mengkaji masalah yang hingga saat ini belum dilakukan upaya yang signifikan untuk mengatasinya. Oleh karena itu dari berbagai masalah yang ada, perlu dibuat lapangan usaha baru berupa pembuatan Kongflake dan diharapkan dapat ditemukan solusinya melalui keterlibatan LPM Universitas Pakuan selaku Tim Pengusul. Penentuan prioritas masalah ini diperkuat dengan adanya kegiatan awal pada sosialisasi program tgl 20 April 2016 sebagai sarana yang dapat meningkatkan tingkat ekonomi masyarakat di kelurahan Karadenan kecamatan Cibinong kabupaten Bogor.

Solusi yang ditawarkan oleh Peneliti Program Studi Kimia Universitas Pakuan untuk permasalahan di kelurahan Keradenan Kecamatan Cibinong Kabupaten Bogor adalah sebagai berikut.

1. Melihat antusiasme masyarakat Kelurahan karadenan yang memiliki semangat kerja yang tinggi sebagai alternatif penyerapan tenaga kerja maka ditawarkan untuk mengisi peluang kerja 
berupa home industry Kongflakes dari tepung singkong.

2. Keterampilan membuat Kongflakes sangat mudah dilakukan dengan baik oleh semua orang tanpa memerlukan latar belakang pendidikan yang tinggi.

3. Pembuatan Kongflakes meskipun sangat mudah dilakukan tetapi butuh sumber daya manusia dengan keterampilan khusus, maka diperlukan pelatihan dan bimbingan secara detail, kontinyu dan tuntas.

4. Salah satu upaya untuk mengatasi masalah modal kerja mitra untuk pembuatan Kongflakes adalah dengan memberikan modal kerja awal antara lain masing-masing mitra diberikan 1 set alat pembuatan kongflakes.

5. Pengemasan dan pelabelan Kongflakes dalam kemasan dapat menjamin kualitasnya selama penyimpanan dan menarik bagi konsumen.

6. Pemasaran merupakan ujung tombak dari suatu produk, sehingga perlu diberikan pengetahuan mengenai tahaptahap pemasaran.

\section{MATERI DAN METODE}

Berdasarkan masalah prioritas yang telah disepakati maka pendekatan yang ditawarkan sebagai solusi yakni sebagai berikut.

1. Memberikan pelatihan keterampilan pembuatan Kongflake untuk skala industri rumah tangga secara detail, kontinyu dan tuntas sampai dihasilkan produk dengan kualitas yang terbaik dengan proses pembuatan sebagai berikut.

a. Pembuatan Tepung Singkong (Latifah, 2014).

Singkong yang telah dikupas dan dibersihkan, kemudian dilakukan penyawutan pada kemudian dikeringkan pada suhu $50-55^{\circ} \mathrm{C}$ selama 20 jam. Proses pengeringan selama 20 jam tersebut akan menghasilkan sawutan singkong kering yang kemudian langsung dilakukan penepungan pada hasil sautan tersebut, kemudian diayak dengan ayakan mesh 80 sehingga dapat diperoleh tepung hasil penyawutan dengan tingkat kehalusan tertentu (foto pembuatan diambil pada saat penelitian awal dengan biaya dari Provinsi Jawa Barat).

b. Pembuatan Kong Flakes (Latifah, 2014)

Bahan-bahan ditimbang sesuai komposisi yang diperlukan. Gula $10 \%$ dan garam $4 \%$ dilarutkan dalam air panas $70^{\circ} \mathrm{C}-80^{\circ} \mathrm{C}$ lalu dicampurkan dengan tepung singkong yang ditambahkan air panas $\left(70^{\circ} \mathrm{C}-80^{\circ} \mathrm{C}\right) \pm 80 \%$ dan diaduk sampai homogen atau kalis. Dibentuk lembaran $(15 \mathrm{~cm} \times 15 \mathrm{~cm} \times 1 \mathrm{~cm})$ lalu dibungkus alumunium foil. Dikukus selama 45 menit dengan suhu $90^{\circ} \mathrm{C}$ $95^{\circ} \mathrm{C}$. Proses ini bertujuan untuk menggelatinisasikan pati pada adonan. Kemudian didinginkan selama 12 jam pada suhu ruangan, agar adonan tidak lengket sehingga memudahkan dalam pencetakan, lalu digiling. Lembaran adonan kemudian dicetak dengan bentuk tertentu. Dipanggang dengan oven pada suhu $150^{\circ} \mathrm{C}$ selama 30 menit lalu didinginkan selama 10 menit (foto pembuatan diambil pada saat penelitian awal dengan biaya dari Provinsi Jawa Barat).

2. Metoda pelatihan pembuatan Kongflakes melibatkan 2 kelompok mitra yang masing-masing beranggotakan 5 orang anggota Kelurahan Karadenan Kecamatan Cibinong kabupaten Bogor, dilakukan melalui beberapa tahapan yaitu sebagai berikut.

a. Pelatihan akan dilaksanakan di Laboratorium Kimia Program Studi Kimia FMIPA Universitas Pakuan. Tahap awal pelatihan dimulai dari 
pemberian materi untuk menambah wawasan mitra mengenai tepung singkong dan kongflakes secara umum dan manfaatnya bagi mitra. Dalam pemberian materi ini juga akan diberikan wawasan tentang cara membuat singkong dan kongflakes yang dihasilkan.

b. Tahap kedua yaitu pelatihan membuat tepung singkong dan kongflakes dengan baik. Dalam pelatihan ini akan diberikan teori tentang cara memilih bahan baku yang baik dan cara membuat tepung singkong yang baik, sehingga dihasilkan tepung singkong dan kongflakes yang berkualitas eksport. Kemudian dievaluasi apakah para mitra sudah dapat menghasilkan menghasilkan Kongflakes dengan kualitas terbaik. Apabila dalam terdapat mitra yang belum berhasil, maka akan diulangi tahap kedua yaitu pelatihan ulang sampai para mitra berhasil.

c. Mendapatkan Ijin Rumah Tangga (IRT) untuk produk Kongflake di Dinas Kesehatan Kabupaten Bogor.

3. Pengemasan

Pengemasan merupakan syarat pokok untuk penjualan sebuah produk pangan, untuk itu perlu dilakukan perlatihan sebagai berikut.

a. Memberikan pelatihan pengemasan dan pelabelan keripik nangka dalam kemasan yang dapat menjamin kualitasnya selama penyimpanan dan menarik bagi konsumen.

b. Sistem pengemasan dan pelabelan harus dibuat sedemikian rupa sehingga konsumen akan tertarik pada produk tersebut dan juga harus memberikan informasi kandungan gizi dan umur produk (tanggal produksi dan kadaluarsa). Pengemasan merupakan sistem yang terkoordinasi untuk menyiapkan barang menjadi siap untuk ditransportasikan, didistribusikan, disimpan, dijual, dan dipakai. Dari segi promosi wadah atau pembungkus berfungsi sebagai perangsang atau daya tarik pembeli. Karena itu bentuk, warna dan dekorasi dari kemasan perlu diperhatikan dalam perencanaannya (Jaswin, 2008).

c. Kemasan yang baik untuk produk kongflakes cukup dengan menggunakan kemasan plastik atau kemasan alumunium dengan melalui proses sealing supaya hampa udara sehingga tidak mudah rusak karena terhindar dari udara dan mikroba, serta diberi label yang menarik yang memuat gambar produk, produsen, berat produk komposisi nilai gizi dan umur produk (tanggal produksi dan tanggal kadaluarsa).

4. Memulai membuat jaringan pemasaran ke berbagai lini pasar

Program IbM yang akan dilaksanakan pada tahun pertama sampai pada tahap memulai membuat jaringan pemasaran. Peluang pemasaran kongflake yang dihasilkan dari industri rumah tangga dapat dipasarkan di toko-toko kecil sampai supermarket. Untuk jangka panjang produk ini dapat dipasarkan secara meluas bahkan sampai eksport yang membutuhkan strategi pemasaran khusus. Bulan keenam akan dilakukan evaluasi apakah para mitra sudah dapat menghasilkan kongflakes yang bermutu baik, apabila ternyata mitra mengalami kesulitan maka akan diadakan pelatihan ulang sampai para mitra berhasil. Keberhasilan program ipteks bagi masyarakat ini dalam jangka pendek adalah peningkatan minat masyarakat untuk membuat kongflake, dengan kualitas terbaik. Sedangkan dalam jangka panjang adalah peningkatan pendapatan masyarakat non produktif melalui wirausaha produksi kongflakes. 


\section{HASIL DAN PEMBAHASAN}

Pada tanggal 14 Maret 2017 dilakukan pertemuan antara Tim Peneliti dengan Bapak Lurah, Ketua PKK dan Sekretaris PKK Keluraran Karadenan Kecamatan Cibinong Kabupaten seperti pada Gambar 2.
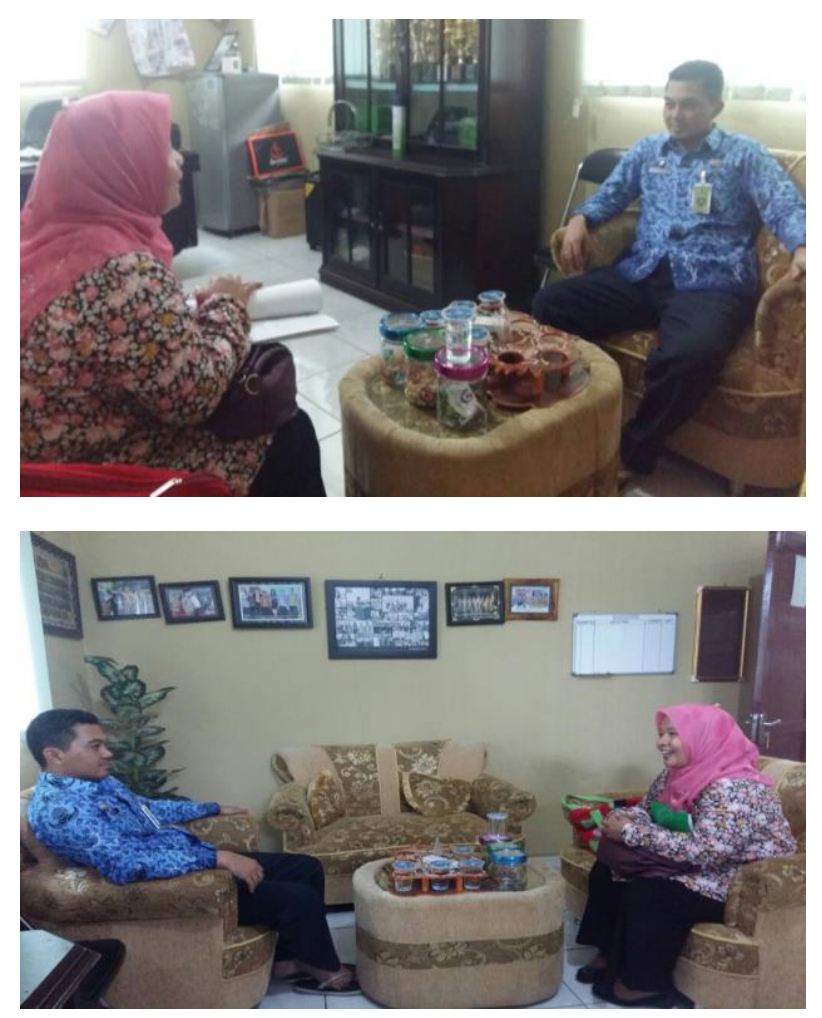

Gambar 2 Pertemuan dengan Lurah Karadenan Kecamatan Cibinong Kabupaten Bogor

Pada pertemuan ini dibahas langkahlangkah yang diambil adalah sebagai berikut.

1. Metoda pelatihan pembuatan Kongflakes melibatkan 2 kelompok mitra yang masing-masing beranggotakan 5 orang anggota Kelurahan Karadenan Kecamatan Cibinong kabupaten BogorPelatihan akan dilaksanakan di
Laboratorium Kimia Program Studi Kimia FMIPA Universitas Pakuan.

2. Tahap awal pelatihan dimulai dari pemberian materi untuk menambah wawasan mitra mengenai tepung singkong dan kongflakes secara umum dan manfaatnya bagi mitra. Dalam pemberian materi ini juga akan diberikan wawasan tentang cara membuat singkong dan kongflakes yang dihasilkan.

3. Tahap kedua yaitu pelatihan membuat tepung singkong dan kongflakes dengan baik. Dalam pelatihan ini akan diberikan teori tentang cara memilih bahan baku yang baik dan cara membuat tepung singkong yang baik, sehingga dihasilkan tepung singkong dan kongflakes yang berkualitas eksport. Kemudian dievaluasi apakah para mitra sudah dapat menghasilkan menghasilkan Kongflakes dengan kualitas terbaik. Apabila dalam terdapat mitra yang belum berhasil, maka akan diulangi tahap kedua yaitu pelatihan ulang sampai para mitra berhasil.

Pada tanggal 12 April dan 17 Mei 2017 bertempat dilakukan Sosialisasi pembuatan Kongflakes Kepada Mitra di Kelurahan Karadenan Kabupaten Bogor, yang dihadiri kader kelompok PKK dengan jumlah Peserta 20 orang perwakilan dari 19 RW. Dalam pertemuan dibahas, mengenai keunggulan dan keuntungan membuat tepung singkong sehingga bisa dibuat berbagai macam produk, terutama porduk flakes (Singkong flakes/KongFlakes) pengganti sarapan yang praktis dan bergizi tinggi. Sosialisasi pembuatan Kongflakes ini dapat dilihat pada Gambar 3. 

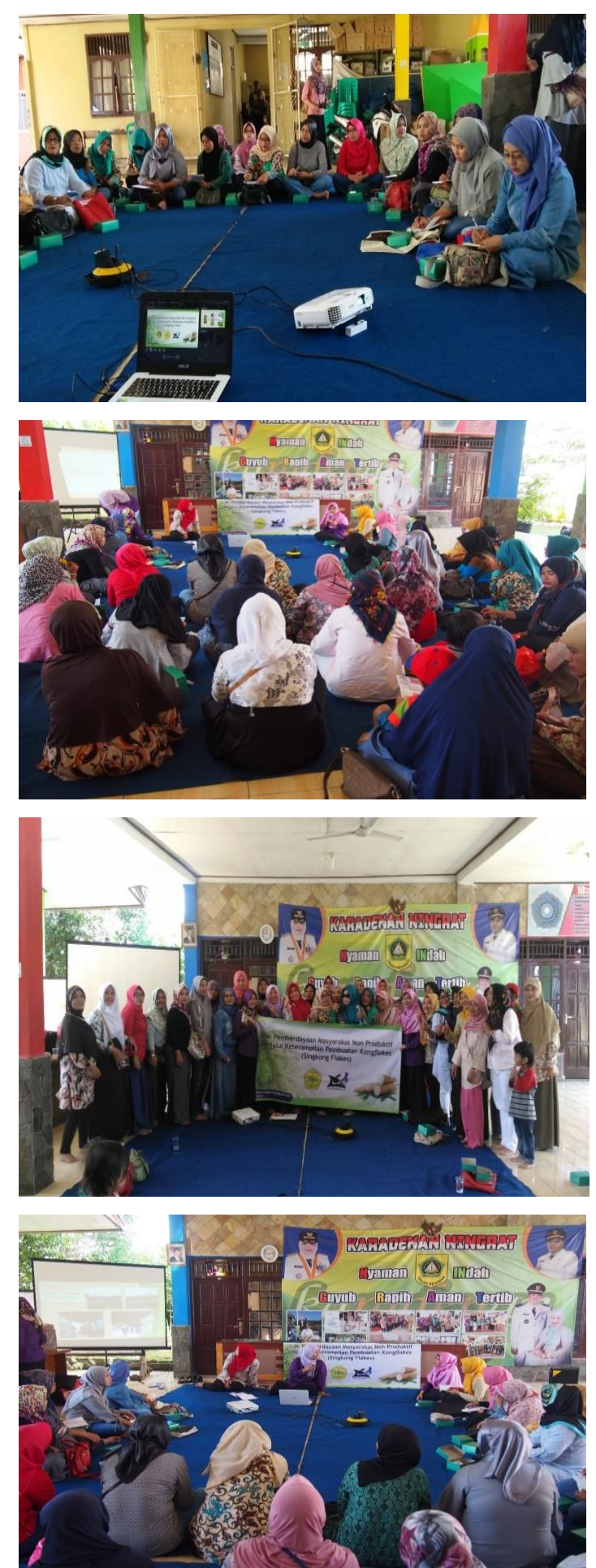

Gambar 3 Sosialisasi pembuatan Kongflakes

Adapun kegiatan lain yang dilakukan ialah melakukan pelatihan pembuatan Kongflakes kepada warga setempat di salah satu rumah warga. Pelatihan tersebut dapat dilihat pada Gambar 4.
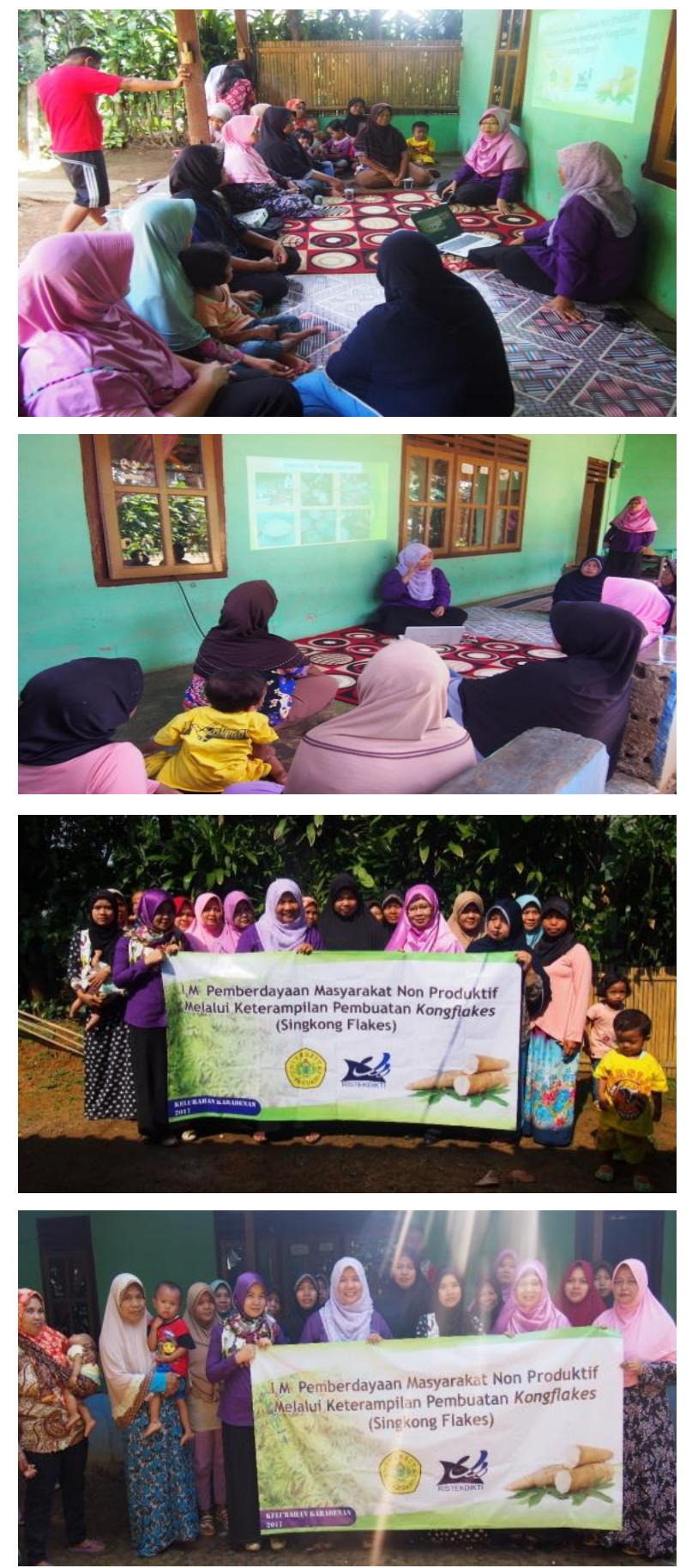

Gambar 4 Pelatihan pembuatan Kongflakes di rumah warga

Indikator jangka pendek keberhasilan program ipteks bagi masyarakat ini adalah peningkatan minat masyarakat untuk membuat Kongflakes, dengan kualitas terbaik. Indikator jangka panjang adalah peningkatan pendapatan masyarakat non produktif melalui wirausaha produksi Kongflakes. 


\section{KESIMPULAN DAN IMPLIKASI}

Dengan diproduksinya Kongflakes di 2 kelompok PKK di Kelurahan Karadenan Kabupaten Bogor menghasilkan :

1. Pembuatan tepung singkong yang mudah pengolahannya, mudah didapat dengan hasil yang maksimum.

2. Pembuatan produk pangan siap santap Kongflakes, membuat variasi penganti sarapan yang praktis dan bergizi tinggi

3. Produksi masal diharapkan dapat membantu ekonomi keluarga.

4. Produksi, pengemasan dan pemasaran masih dalam pemantauan tim peneliti.

Hasil pengabdian masyarakat di Kelurahan Karadenan diharapkan dapat berdampak positif untuk masyarakat nonproduktif Kelurahan Karadenan yaitu terciptanya lapangan pekerjaan dalam pembuatan Kongflakes yang dapat meningkatkan pendapatan dari masyarakat tersebut, yang selanjutnya diharapkan produk Kongflakes ini bisa menjadi salah satu icon dari Kelurahan Karadenan khususnya dan Kabupaten Bogor dan Universitas Pakuan secara umum.

\section{UCAPAN TERIMA KASIH}

Terima kasih kepada Direktorat Riset dan Pengabdian Masyarakat, Direktorat Jenderal Penguatan Riset dan Pengembangan, Kementerian Riset, Teknologi dan Pendidikan Tinggi atas pendanaan dan kepercayaannya yang diberikan agar bisa terlaksananya kegiatan pengabdian kepada masyarakat ini. Terima kasih kepada M. Erik Kurniawan yang telah membantu dalam pelaksanaan penelitian ini.

\section{DAFTAR PUSTAKA}

Latifah, I. (2014). Peningkatan nilai gizi produk olahan flakes berbasis tepung singkong (Manihot esculenta Crantz) dengan penambahan tepung kacang merah (Phaseolus vulgaris L.). Skripsi. Program Studi Kimia Fakultas Matematika dan Ilmu Pengetahuan Alam. UNPAK: Bogor.

Soesanto, E. (2008). Tepung Cassava dan Olahannya. Kanisius: Yogyakarta.

Soewarno et. al. (2008). Pengembangan diversifikasi produk untuk industri pangan berbasis pangan lokal. Laporan Penelitian Ilmu Pengetahuan Terapan. Balai Besar Industri Agro: Bogor.

Tjiptadi, W. (1981). Umbi Ketela Pohon sebagai Bahan Industri. Jurusan Teknologi Industri Pertanian. FATETAIPB: Bogor.

Winarno, F.G. (1992). Kimia Pangan dan Gizi. Gramedia Pustaka Utama: Jakarta.

Widiastuti, D., Herlina, E., Mulyati, A.H. (2015). Pengembangan Produk Kongflakes Berbasis Singkong (Manihot esculenta) yang Diperkaya Tepung Ampas Kelapa sebagai Sumber Pangan Lokal. Seminar Hasil-hasil Penelitian Kegiatan Peningkatan Kualitas Penelitian Dosen PTS dan Politeknik untuk Pembangunan Jawa Barat.

Widiastuti, D., Herlina, E., Mulyati, A.H., Warnasih, S. (2016). Diversification of Cassava Flour in the Manufacture of Gluten-Free Flakes Enriched with Dietary Fibers from Virgin Coconut Oil Waste Flour. Journal of Agricultural Science and Technology B 6 (6): 418-423 doi: 10.17265/2161-6264/2016.06.007. 